\title{
Successful medical management of uterine arteriovenous malformation
}

\author{
Aparajita Rastogi*, Neetu Kumari, Sarita Rajbhar, Pushpawati Thakur, Sagarika Majumdar
}

Department of Obstetrics and Gynaecology, AIIMS Raipur, Chhattisgarh, India

Received: 16 April 2021

Accepted: 10 May 2021

\section{*Correspondence:}

Dr. Aparajita Rastogi,

E-mail: aparajitarastogi@gmail.com

Copyright: () the author(s), publisher and licensee Medip Academy. This is an open-access article distributed under the terms of the Creative Commons Attribution Non-Commercial License, which permits unrestricted non-commercial use, distribution, and reproduction in any medium, provided the original work is properly cited.

\begin{abstract}
Uterine Arteriovenous malformation (AVM) is defined as abnormal communication between the uterine arteries and veins. This can be congenital or acquired. It occurs more frequently in reproductive age group women. Patient present with complain of spotting per vagina to catastrophic bleeding per vaginum. Diagnosis is based upon clinical history and findings in colour doppler of pelvis. The treatment depends upon the age of the patient, her symptoms, age, desire of future fertility and localization and size of the lesion. Uterine artery embolization is the most commonly used treatment for symptomatic uterine arteriovenous malformation. There were few case reports of successful medical management of uterine AVM with GnRH agonist. But GnRH agonist have side effects that restrict its long time use and for Uterine artery embolization, clinical skill and set up is required and it is not available at every hospital. Here is presenting a case report of successful medical management of uterine arteriovenous malformation with combined oral contraceptive pills (coc). COC are easily available everywhere and its side effects are few if compared with GnRH agonist.
\end{abstract}

Keywords: Arteriovenous malformation, Combined oral contraceptive, Abnormal uterine bleeding

\section{INTRODUCTION}

Uterine arteriovenous malformation (AVM) is defined as abnormal communication between the uterine arteries and veins. This can be congenital or acquired (secondary to dilatation and curettage, therapeutic abortion, cervical or endometrial cancer, trophoblastic diseases, and direct uterine trauma). It occurs more frequently in women in reproductive age. Congenital AVMs are extremely rare conditions, whereas the incidence of acquired AVM is currently increasing. ${ }^{1-5}$ It is a rare condition. The reported cases in literature are about 100. AVM usually presents with abnormal uterine bleeding (AUB) ranging from spotting per vagina to catastrophic hemorrhage requiring multiple blood transfusions and acute morbidity amongst women. Diagnosis is based upon clinical history, high index of suspicion and diagnostic findings in colour doppler and when there is diagnostic dilemma, it requires pelvic angiography and lastly it is diagnosis of exclusion in cases of AUB. The treatment of choice depends on the symptoms, age of the patient, desire for future fertility and localization and size of the lesion. Uterine artery embolization is the most commonly used treatment in symptomatic AVM and patients desiring for future fertility. There are only few cases reported with successful medical management with GnRH agonist. We present the case report of AVM managed successfully with continuous use of combined oral contraceptive pills.

\section{CASE REPORT}

A 29 years old parity 1 (1 living child) lady presented to AIIMS OPD with complaints of bleeding per vaginum for last 10 days. She gave history of medical abortion after 9 days of overdue of mens. After 6 weeks of medical abortion, she had heavy bleeding per vaginum for which she consulted at a private clinic where check curettage was done but its histopathological report was not available. She consulted at AIIMS, Raipur in OPD with complain of bleeding per vaginum for 10 days. On Initial assessment, her general condition was satisfactory with moderate 
pallor. On speculum examination mild bleeding was present through cervix. 2D Ultrasound was done, which did not show any product of conception with endometrial thickness $5 \mathrm{~mm}$. Her haemoglobin was $8 \mathrm{gm} / \mathrm{dl}$. Other investigations were within normal limit. She was started on hematinic and Oral contraceptive pills (OCP) once daily for 21 days but she stopped taking medications after 10 days. After 3 days of stopping OCP, she presented in emergency (AIIMS, Raipur) with profuse bleeding per vaginum. On examination she was having tachycardia (pulse rate-130 bpm), hypotension (BP 90/50 $\mathrm{mmHg}$ ) with severe pallor. On speculum examination fresh blood was coming through os. Urine pregnancy test was negative. Her haemoglobin was $4.5 \mathrm{gm} \% .3$ units of Packed red cell (PRBC) transfusion done. Along with conservative management, her bleeding was stopped with twice daily dose of OCP. Further investigations were done. On 3D Sonography on Gray scale, uterus was bulky with diffuse homogenecity in the anterior myometrium with diffuse grade 4 vascularity. On colour doppler, there was area of increased vascularity seen in the anterior myometrium with multiple enlarged uterine vessels with turbulent high flow with the differential diagnosis as gestational trophoblastic neoplastic disease (GTND), Retained product of conceptus (RPOC), placental site trophoblastic tumour (PSTT), AVM
(Figure 1). Beta $\mathrm{HCG}$ was $0.256 \mathrm{Miu} / \mathrm{ml}$ (ruling out GTND), human placental lactogen (HPL) $<0.1$ microgram (ruling out PSTT). Her coagulation profile were normal. A diagnosis of AVM with severe anemia was made. Bleeding stopped after 4 days of OCP. she was discharged from the hospital with advice to take oral contraceptive pills continuously for three months and with a plan of uterine artery embolization later. After three months follow up, she reported no further bleeding per vaginum. Repeat Doppler showed regression of high uterine vascularity (Figure 1). She was advised further to continue contraceptive pills as she was desirous of contraception as well. At 6 months follow up she is having regular menstrual cycle and continuing OCP for contraception with no episode of any bleeding irregularity.

\section{DISCUSSION}

Uterine AVM is a rare but life-threatening condition in which patient presents with vaginal bleeding that may be profuse and can cause hemodynamic instability. It is important to diagnose uterine AVM correctly, in order to start appropriate management.

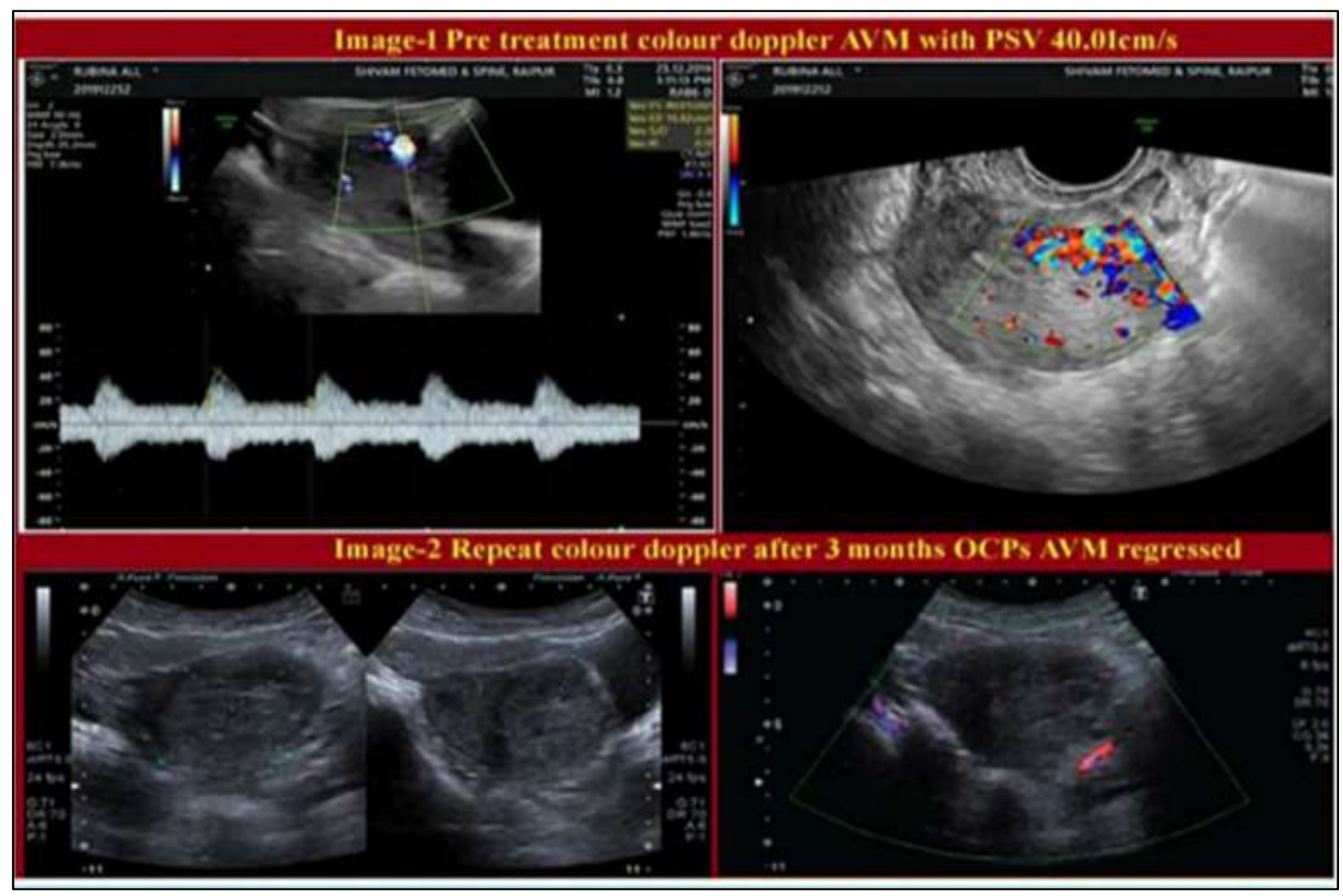

Figure 1: (Image 1) Saggital endovaginal powder and colour doppler view of uterus before treatment showing multiple tortuous vessels in myometrium. (Image 2) Saggital endovaginal colour doppler view of uterus showing decreased vascularity after treatment. 
Pelvic sonography is often the initial screening study performed in the setting of suspected pelvic or uterine AVM and should include the use of colour Doppler with flow velocity measurements. Gray scale sonographic findings can be nonspecific and may include myometrial thickening and inhomogenecity, an intramural or endometrial mass, tubular spaces within the uterine wall, and enlarged parametrial vessels. Colour doppler evaluation should be used to document the presence of multiple enlarged uterine and/or pelvic vessels with intense signal, aliasing, and apparent flow reversal indicative of turbulent high-velocity flow (Figure 2). Spectral doppler demonstrating elevated flow velocities within low-resistance vessels indicates the presence of an arteriovenous communication. Resistive indices will often be between 0.25 and $0.55 .^{6}$

The differential diagnosis includes- gestational trophoblastic neoplasia (Raised beta HCG), Placental site Trophoblastic tumour (HPL), retained product of conceptus as these may also present with abnormal uterine bleeding and hypervascularity with turbulent flow on USG doppler. However, in this patient, undetectable beta HCG level and normal HPL (Human Placental Lactogen), helped in ruling out these possibilities.

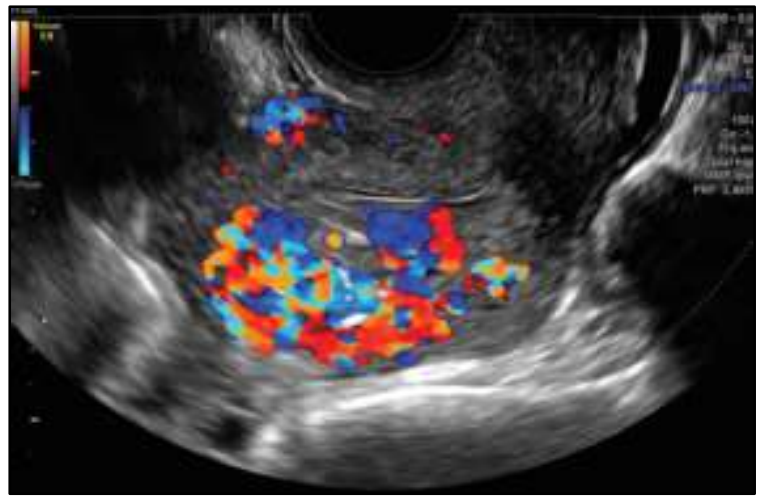

Figure 2: Sagittal colour doppler ultrasound of the uterus demonstrating markedly increased flow with aliasing, primarily within the myometrium.

Peak systolic velocity (PSV) within the AVM can help to guide its management. A PSV $\leq 40 \mathrm{~cm} / \mathrm{s}$ identifies AVMs that are likely to regress without intervention and may be managed expectantly with periodic sonographic follow-up in haemodynamic stable patients. A PSV $>60 \mathrm{~cm} / \mathrm{s}$ indicates a more concerning AVM with a low likelihood of spontaneous regression and potential risk of significant bleeding even in a currently stable patient and these highvelocity AVMs should be treated expeditiously. AVMs with PSV between 40 and $60 \mathrm{~cm} / \mathrm{s}$ may be managed with close interval sonographic follow-up in patients without excessive bleeding, as they may regress or persist. ${ }^{7}$

In this case, the patient had profuse vaginal bleeding and an abrupt fall in hemoglobin $(4.4 \mathrm{gm} \%)$ and her USG with doppler was suggestive of left uterine AVM with low impedance high velocity flow (mean PSV: $40.01 \mathrm{~cm} / \mathrm{s}$ ). Hence, after an initial hemodynamic stabilization with 3unit PRBC transfusion and injection tranexamic acid, she was planned for uterine artery embolization. However, she responded well with OCPs and after three months continuous intake of OCPs the repeat doppler revealed regression of AVM.

The probable mechanism by which the continuous use of OCP might have helped in this condition are: continuous use of OCPs induce amenorrhea and endometrial decidualization and also enhancing apoptosis in endometrium, continuous use of OCP prevent cyclical shedding of endometrium and ischemic necrosis of the vessels avoiding abrasions of vessels in AVM. ${ }^{8}$

\section{CONCLUSION}

Uterine and pelvic AVMs are rare cause of excessive and potentially catastrophic vaginal bleeding. The incidence of acquired AVM is increasing. Endovascular management with transcatheter embolization9 is the mainstay of therapy for both uterine and pelvic AVMs. However, it is costly and requires trained personnale. Hysterectomy is the definite treatment but surgical management is avoided in young patients. Growing evidence suggests that conservative management may be appropriate for many patients with uterine AVMs. There is role of GnRH Agonist in its treatment in some studies but it is costlier and its continuous use leads to osteoporotic changes. We suggest use of oral contraceptive pills which is a cost effective, easily available as well associated with lesser side effects and complications. However further research is needed to establish its efficacy.

Funding: No funding sources

Conflict of interest: None declared

Ethical approval: Not required

\section{REFERENCES}

1. O'Brien P, Neyastani A, Buckley AR, Chang SD, Legiehn GM. Uterine arteriovenous malformations: from diagnosis to treatment. Journal of Ultrasound in Medicine. 2006;25(11):1387-92.

2. Yazawa H, Soeda S, Hiraiwa T. Prespective evaluation of the incidence of uterine vascular malformations developing after abortion or delivery. J Minim Invasive Gynecol. 2013;20;360-7.

3. Halperin R, Schneider D, Maymon R, Peer A, Pansky M, Herman A. Arteriovenous malformation after uterine curettage: a report of 3 cases. The Journal of Reproductive Medicine. 2007;52(5):445-9.

4. Cura M, Martinez N, Cura A, Dalsaso TJ, Elmerhi F. Arteriovenous malformations of the uterus. Acta Radiologica. 2009;50(7):823-9.

5. Grivell RM, Reid KM, Mellor A. Uterine arteriovenous malformations: a review of the current literature. Obstetrical and Gynecological Survey. 2005;60(11):761-7. 
6. Yan X, Zhao C, Tian C. Ultrasound guided high intensity focused ultrasound ablation for treating uterine arteriovenous malformation. BJOG. 2017;124:93-6.

7. Yoon Dj, Jones M, Al Taani J. A systemic review of acquired uterine arteriovenous malformation: pathophysiology, diagnosis and transcatheter treatment. AJP Rep. 2016;6:e6-14.

8. Timor-Tritsch IE, Haynes MC, Monteagudo A. Ultrasound diagnosis and management of acquired uterine enhanced myometrial vascularity/arteriovenous malformations. Am J Obstet Gynecol. 2016;214:731.e1-10.

9. Wang Z, Chen J, Shi H. Efficacy and safety of embolization in iatrogenic traumatic uterine vascular malformation. Clin Radiol. 2012;67:541-3.

Cite this article as: Rastogi A, Kumari N, Rajbhar S, Thakur P, Majumdar S. Successful medical management of uterine arteriovenous malformation. Int J Reprod Contracept Obstet Gynecol 2021;10:2519-22. 